NASA/TM-2000-210234

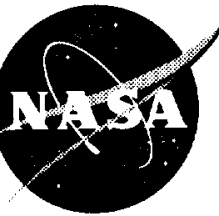

\title{
Assessment of the Stirling Power Option for Space Science Applications
}

Jeffrey G. Schreiber

Glenn Research Center, Cleveland, Ohio

Prepared for the

2000 Aerospace Conference

sponsored by the Institute of Electrical and Electronics Engineers

Big Sky, Montana, March 18-24, 2000

National Aeronautics and

Space Administration

Glenn Research Center

July 2000 


This report contains preliminary
findings, subject to revision as
analysis proceeds.

Available from

NASA Center for Aerospace Information 7121 Standard Drive

Hanover, MD 21076

Price Code: A03
National Technical Information Service 5285 Port Royal Road Springfield, VA 22100 Price Code: A03 


\title{
Assessment of the Stirling Power Option for Space Science Applications
}

\author{
Jeffrey G. Schreiber \\ National Aeronautics and Space Administration \\ Glenn Research Center \\ Cleveland, Ohio 44135
}

\begin{abstract}
Free-piston Stirling technology efforts in the past typically were intended to address power needs in the multikilowatt range. The Stirling power option was attractive primarily because of the high conversion efficiency and potential for long life. In recent years, several technology efforts have focused on the free-piston Stirling power convertor for space power applications, however the more recent efforts are intended to provide power at levels far below one kilowatt. Through a variety of projects funded by both NASA and DOE, the free-piston Stirling convertor technology has successfully demonstrated high efficiency and long life. Other areas of concern, such as control of multi-convertor systems, and vibration reduction have also been addressed. Efforts are being initiated to address issues such as electro-magnetic interference (EMI), radiation tolerance of organic materials, and the ability to operate through launch loads and survive with integrity. The status of the technology in these areas will be briefly discussed in this paper.
\end{abstract}

\section{INTRODUCTION}

The Thermo-Mechanical Systems branch at the NASA Glenn Research Center (GRC) is responsible for developing a wide variety of advanced technologies for future spacecraft. Among the technologies that are currently being pursued are inflatable solar concentrators that may potentially be used for earth orbiting solar thermal systems (furnace for material processing, power conversion, or propulsion), and a novel Refractive Secondary Concentrator (RSC) intended primarily for solar thermal propulsion. These technologies can be combined to work with one another to form an optical system for the chosen application. The major effort within the branch centers on free-piston Stirling power convertors for potential use with a radioisotope heat source to provide power for deep space missions.

The free-piston Stirling convertor has long been considered a candidate for a wide variety of space power applications, in part because of the demonstrated high conversion efficiency, and also because of the potential for long life. In an earlier paper a novel solar power system was proposed that incorporates the free-piston Stirling convertor along with the inflatable primary concentrator and the RSC [1]. A brief study indicated that this power system option could supply power for space science missions to Jupiter and possibly for Saturn [2]. Each of these optical technologies will be briefly discussed later in this paper. A much larger effort within the branch has centered on addressing specific requirements that must be met for a dynamic power system to be considered for a mission. Dynamic power systems have often been studied for a variety of applications [3] and missions, however, rarely have these efforts progressed to a point where the hardware is being judged against a full set of mission requirements. This would include considerations of launch loads, electro-magnetic interference (EMI), and radiation effects on organic materials along with a failure modes and effects analysis (FMEA).

There has long been interest in developing a power system for deep space exploration that reduces the inventory of the isotope fuel (plutonium) needed, or potentially eliminates the need entirely. The radioisotope thermoelectric generator (RTG) used in the past has proven itself to be very rugged and highly reliable, however the relatively low conversion efficiency requires a large inventory of plutonium contained in the General Purpose Heat Source (GPHS) blocks. For reasons of environmental concerns and mission cost, a highly efficient conversion system requiring less plutonium, or possibly eliminating the plutonium would be highly desirable.

The Department of Energy (DOE) and NASA GRC are developing a free-piston Stirling convertor to be integrated into a high efficiency radioisotope electric power conversion system for possible use in future space missions. The Technology Demonstrator Convertor (TDC) is shown in figure 1. The TDC was designed and built by the Stirling Technology Company (STC) of Kennewick, WA. A 1997 study team with joint participation from NASA and DOE determined that the Stirling conversion option was a low risk alternative with dependable background of materials, lifetime, and demonstrated performance [4], [5]. 


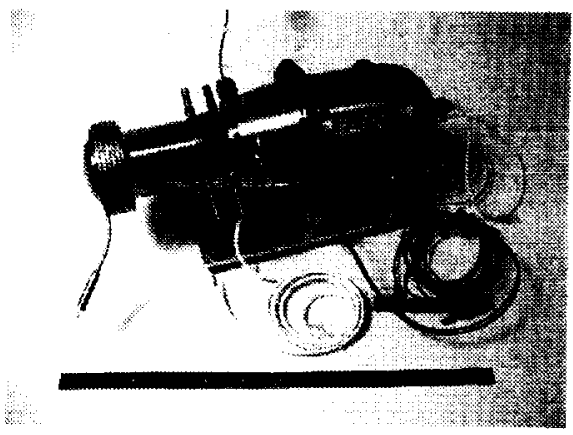

Figure 1 A 55 We Free-Piston Stirling Technology Demonstrator Convertor.

A novel system investigated in the past was the power antenna [6], [7] which used an inflatable parabolic reflector that served two purposes. It functioned as a reflector for the communications system, and also as a solar reflector for the power system. The power conversion technology used was a photovoltaic array situated in concentrated sun light, in the general region of the focal spot. Through a NASA SBIR, L'Garde investigated this option and proposed that it had merit for low power missions, potentially to Jupiter (5.2 AU) and Saturn (9.5 AU).

A system was subsequently conceived at NASA GRC that uses a free-piston Stirling power conversion system intended for use with a radioisotope heat source, and integrates it with an inflatable primary concentrator, and the refractive secondary concentrator. This produces a relatively low power level (less than $1 \mathrm{kWe}$ ) solar dynamic power system. It is believed that with careful consideration of system level trades, a system could be configured that provides a viable isotope-free power system option for space science missions. After conceptualizing the system, a brief study was performed that indicated that the system indeed may be advantageous for some space exploration missions [2]. A key feature is that all of the subsystems are currently being developed under existing projects, and that the system was conceived by merely exploiting the synergism that exists when the three technologies are combined to form a power system.

\section{OVERVIEW OF THE TECHNOLOGIES}

A very brief description will be given of each of the optical technologies that have been incorporated into the aforementioned solar Stirling power system, followed by a description of the free-piston Stirling technology and the issues that are being addressed. The description will include the characteristics of the technology, a description of the intended applications, and an indication of the status of development.

\section{Primary Solar Concentrators}

The NASA GRC has had a longstanding interest in the development of advanced, lightweight solar concentrators. Efforts at GRC date back to the early 1960's with the development of rigid concentrators and deployable concentrators with rigid facets. In an early effort with TRW, a deployable concentrator known as the Sunflower was developed. The name Sunflower was chosen based on the arrangement of the hinged pedals that surrounded a central hub. A subsequent effort at GRC in 1965 produced a 6 meter diameter magnesium concentrator with a specific mass of $4.7 \mathrm{~kg} / \mathrm{m}^{2}$. In the early stages of Space Station Freedom (SSF) program, one of the power system options considered was a hybrid system including both photovoltaic and solar dynamic Brayton power conversion. In 1989, a concentrator was developed for SSF based on a box-beam supporting structure with multiple triangular facets. The 456 facets, without the supporting structure had a specific mass of $2.4 \mathrm{~kg} / \mathrm{m}^{2}$. In 1994 a system level test was performed using a downsized version of the SSF concentrator, as shown in figure 2. The specific mass of the concentrator including supporting structure was approximately $11.1 \mathrm{~kg} / \mathrm{m}^{2}$.

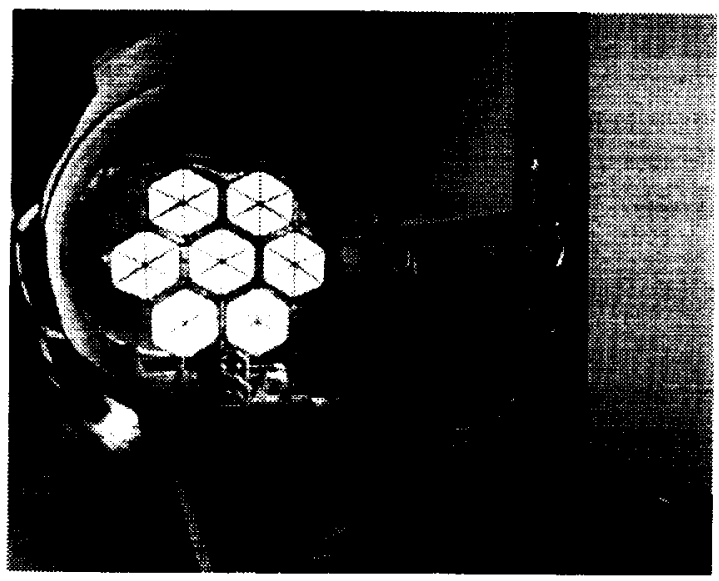

Figure 2 A Rigid Concentrator Used During The Brayton Solar Dynamic Power System Test at GRC.

Lightweight deployable designs, such as the Spline Radial Panel concentrator proposed by Harris Corporation, could reduce the mass to approximately $2 \mathrm{~kg} / \mathrm{m}^{2}$, however this technology has not been demonstrated as a solar concentrator. Thin film inflatable technology offers the potential to reduce the mass of solar concentrators even further, to less than $1 \mathrm{~kg} / \mathrm{m}^{2}$. Companies such as $\mathrm{SRS}$ Technologies, ILC Dover, United Applied Technologies, and L'Garde are developing technology that is applicable to large thin film inflatable concentrators. The Inflatable Antenna Experiment by L'Garde in 1994, as shown in figure 3 , was a major step forward in demonstrating the potential of 


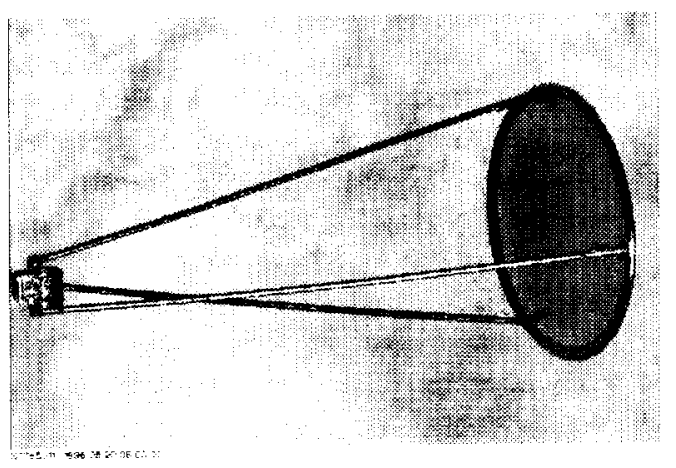

Figure 3 Inflatable Antenna Experiment by L'Garde.

this technology. Inflatables had previously flown in space, however this was the first demonstration in space of a parabolic reflector supported by a torus and struts.

There is also interest in using light weight concentrators for solar thermal propulsion systems [8]. Solar thermal propulsion could provide an option for orbit transfer and inspace maneuvers with specific impulse and thrust levels being somewhere between those achieved with chemical propulsion and electric propulsion. The high temperature requirement for this application translates into high optical accuracy requirements for the primary concentrator.

Recognizing that the requirements placed on a solar concentrator for either solar thermal propulsion or power are similar, GRC has been coordinating efforts with the Air Force Research Laboratory (AFRL) in the development of inflatable concentrators. A Phase I SBIR contract with SRS Technologies of Huntsville, AL produced a technology demonstration inflatable concentrator shown in figure 4 . In collaboration with AFRL, this concentrator was subsequently tested in the Tank 6 solar thermal vacuum facility at GRC. The concentrator achieved approximately $2 \mathrm{mrad}$ slope error, which is sufficient accuracy for some

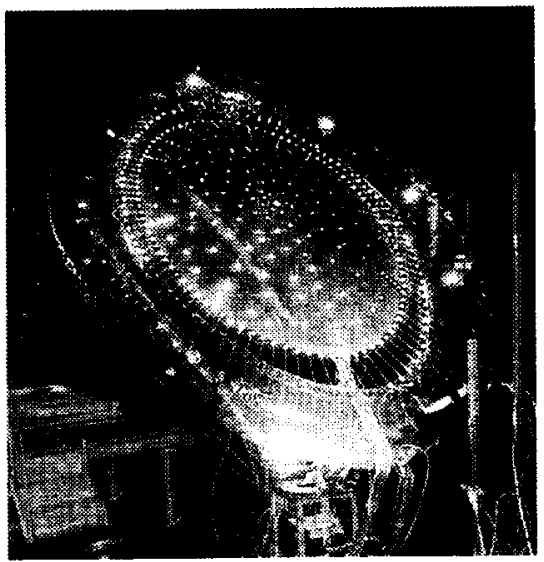

Figure 4 SRS Solar Concentrator Being Installed in GRC Tank 6 for Testing. solar thermal applications. The SBIR Phase II effort is currently underway.

\section{Refractive Secondary Concentrator}

An effort is underway at NASA GRC to develop a highly efficient secondary solar concentrator. It is based on an innovative, single crystal RSC which uses the principle of total internal reflection. The RSC alleviates some of the limitations of reflective secondary concentrators in terms of concentration ratio, efficiency, and distribution of the flux exiting the concentrator. Concentration ratios of 25:1 appear to be possible with the RSC. and efficiency at high power is projected to be $90 \%$ or greater. When used with a high quality primary concentrator, this allows a total concentration ratio (i.e., the primary and secondary concentrators combined) on the order of $10,000: 1$. A prototype RSC is shown in figure 5 .

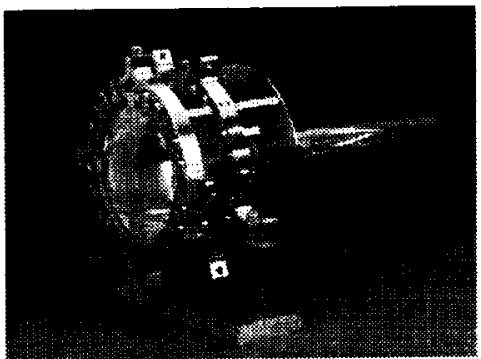

Figure 5 Refractive Secondary Concentrator at GRC.

The RSC designs analyzed and tested thus far perform two distinct functions. First, the conical segment concentrates the light via total internal reflection. Secondly, the extractor can be used to transport the solar flux deep into a receiver cavity. The extractor can then be tailored to deliver the flux with a favorable distribution. The ability of the extractor to transport the energy deep into the receiver differs from the reflective secondary concentrators which tend to distribute the flux near the aperture of the receiver.

The effort at GRC has been directed primarily toward the use of this technology for solar thermal propulsion where a high concentration ratio to achieve high temperature in the receiver is necessary. Other applications would be for solar thermal furnaces and possibly for solar thermal power conversion. While the development of the RSC is in its early stages, the results are very promising [9]. The use of the RSC can have a significant impact on the requirements for the primary concentrator. For example, in an optimized system it may be possible to relax the accuracy requirements on the primary concentrator, and a mass or cost savings may be realized. 


\section{Stirling Poner Convertor}

DOE and NASA are developing a Stirling convertor for possible use in a high efficiency radioisotope electric power system for possible use on future deep space missions. A 1997 study team with joint participation from NASA and DOE determined that the Stirling conversion option was a low risk alternative with dependable background of materials, lifetime, and demonstrated performance. The Advanced Radioisotope Power System (ARPS) project was initiated and went forward with the Alkali Metal Thermal to Electric Converter (AMTEC) as the conversion technology. Subsequently, a low level effort was initiated to investigate the feasibility of the free-piston Stirling power convertor [10], [11]. This effort was performed primarily through a DOE contract with STC, however it was also supported by NASA GRC through Small Business Innovation Research (SBIR) contracts in addition to GRC in-house capabilities led by the Thermo-Mechanical Systems Branch. This effort has resulted in the design of the $55 \mathrm{We}$ free-piston Stirling TDC, which has demonstrated full power and predicted efficiency. Figure 1 shows one of the 55 We convertors, while figure 6 shows two of the convertors mounted as a dynamically opposed, balanced pair. The technologies used in these $55 \mathrm{We}$ convertors have previously been used by STC in a 350 We convertor, and in a 10 We convertor that has demonstrated long life with over 53,000 hours of continuous operation with no degradation. This was achieved by eliminating the life limiting and performance degrading mechanisms from the design.

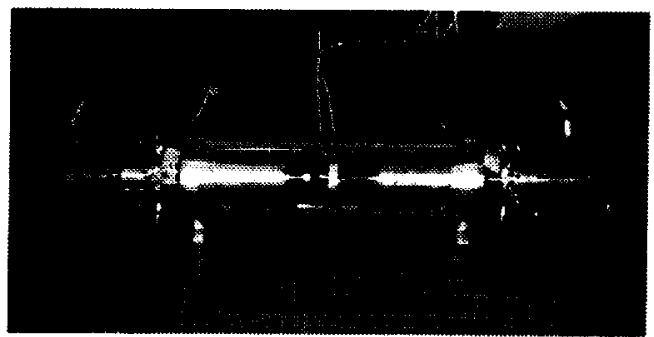

Figure 6 A Pair of 55 We Stirling Convertors Demonstrating Low Vibration Operation.

As work has progressed on the $55 \mathrm{We}$ TDC, many of the previous concerns regarding the use of free-piston Stirling convertors have been successfully resolved. Synchronous operation with multiple convertors that are thermodynamically independent of one another has been demonstrated. Synchronous operation of pairs of convertors leads to a dynamically balanced system with very low residual vibration. An Advanced Vibration Reduction System (AVRS) has also been developed to further reduce vibration [12]. Preliminary results from recent tests and analysis indicate that residual vibration is within acceptable levels for space science missions.
Past projects at GRC often pushed the state-of-the-art in material and structural requirements, and fabrication techniques. For example, new materials were required for the Automotive Stirling Engine Project of the 1980's, and the engine was thus able to meet the technical goals of the program. Advanced fabrication techniques were required for the Component Test Power Convertor (CTPC) free-piston Stirling of the SP-100 program, and similarly, this engine achieved the expected level of performance. The TDC is based on standard materials and commonly used fabrication processes, which reduces the manufacturing cost and allows for unit-to-unit replication of performance.

\section{DESCRIPTION OF THE POWER SYSTEMS}

\section{The Isotope Power System}

With the Stirling convertor technology for this application progressing, attention has started to focus on power conversion system issues. Under contract to DOE, Lockheed Martin Astronautics (LMA), Valley Forge, PA, is developing and studying system concepts. Previously, Orbital Science Corporation (OSC) had developed system concepts [13], of which one is shown in figure 7. These concepts are based on the use of GPHS blocks for heat input, the $55 \mathrm{We}$ TDC for thermal-to-electric power conversion, and existing technology radiators for heat rejection. The TDC is designed to operate at nominal temperatures of $650^{\circ} \mathrm{C}$ hot end temperature and $120^{\circ} \mathrm{C}$ cold end temperature. Efficiency of the Stirling (thermal in to electric output) is approximately $27 \%$ at the design conditions. In the intended application, the temperatures would vary over the life of the mission as the isotope decays and as the radiator views a changing sink temperature.

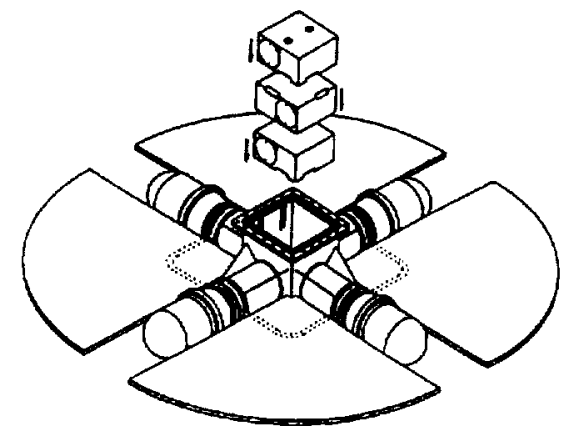

Figure 7 Radioisotope Stirling Power System Concept Proposed by Orbital Science Corporation. 
In the concept shown, an insulated cavity exists in the center of the structure where the GPHS blocks would be housed. The housing acts as a structure to which the Stirling convertors are mounted, and it also contains the multi-layer insulation (MLI) that surrounds the GPHS blocks. Although a variety of configurations have been studied, the highly insulated structure for the GPHS blocks remains a common feature.

With the technology currently in the TDC. the mass is approximately $6.0 \mathrm{~kg}$ per 55 We unit. For a flight unit, the mass would be reduced as 1) the bolted flanges of the developmental design would be converted to welded joints, and 2) the instrumentation used during the developmental stages is eliminated. It is believed that the mass would approach $4.0 \mathrm{~kg}$. The mass could be further reduced if advanced technology was incorporated. Concepts exist for smaller, lighter alternators however these require some development before they could be considered for use in a mission. With the advanced technology, the mass could approach $3.0 \mathrm{~kg}$ per $55 \mathrm{We}$ convertor.

\section{The Solar Dynamic Power System}

The ARPS program is based on the desire of both NASA and DOE to have an advanced radioisotope power system with higher efficiency than the RTGs, thus requiring less plutonium. Extending this logic would lead one to develop a power system for deep space missions that needs no plutonium at all. Such a system was envisioned at GRC by integrating the technologies that have been discussed earlier in this paper: that is, a system with a lightweight inflatable primary concentrator, a high efficiency refractive secondary concentrator, and a high efficiency free-piston Stirling power convertor. When compared to solar dynamic power systems that have been studied and tested in the past, the proposed system has some distinct characteristics[1]. By considering the unique traits of the individual technologies, system level trades were performed that are different than experienced in previous systems.

By taking advantage of the high concentration ratio and high efficiency of the RSC, the accuracy requirements levied on the primary concentrator can be relaxed. This feature should result in savings in terms of both mass and cost. System level analysis is necessary to determine the final configuration of the optical concentration system, i.e. the primary and secondary concentrators as a system. The RSC also incorporates an extractor which can take the solar energy deep into a cavity, and deposit it in a predetermined distribution. This solar concentration system would then be integrated with a free-piston Stirling based power conversion system. The power conversion system would be strongly based on the system being investigated for use with an isotope heat source, however the cavity intended to hold the GPHS blocks would now act as a solar receiver cavity. The extractor of the RSC would take the solar flux into the cavity designed for the GPHS blocks, however the cavity would now be heated with the solar energy. An initial study concluded that a $200 \mathrm{~W}$ solar Stirling. system of the type described is competitive with radioisotope power systems out to $10 \mathrm{AU}$ and is projected to have a specific power of $5.9 \mathrm{~W} / \mathrm{kg}$ in this size range [2]. A further extension of the system would use the primary concentrator as proposed in the study of the power antenna, and thus it would perform duties for both the power system and the communication system.

The proposed system leads to a highly integrated spacecraft which might be suitable for a range of deep space missions. Missions to Mars may be best served with a photovoltaic power system because the solar intensity is still relatively high. Similarly, missions to Neptune or Pluto may require unreasonably large primary solar concentrators because of the extremely low solar intensity, and thus may be better served with a high efficiency isotope power system. However, it is believed that there may be a range of missions that could benefit from using the proposed non-isotope power system. If these missions can be performed using the proposed power system, then there are great benefits incurred with the elimination of the isotope fuel. These benefits are in terms of both environmental concerns and cost. The cost savings is on the order of 10 's of millions of dollars per mission.

\section{System Requirements}

A review of the literature proposing the use of free-piston Stirling convertors in the past would show that the words "potential for" were often attached to many items on a list of attributes. Today, the "potential for" can be changed to read "proven" for a number of challenging requirements. This is due to a wide variety of reasons which includes the support of NASA and DOE, along with advances that have been fostered by commercial interest in the technology. One of the key areas that has changed is life and reliability. Through sound engineering practices, the performance degrading and life limiting wear mechanisms have been eliminated. In some designs, such as the TDC, life is limited by creep in the heater head, which can be accurately analyzed. Hermetic sealing of units has been demonstrated in a number of designs, and is a design and fabrication issue, not a technology issue. Replication of performance has been demonstrated in a number of designs and merely requires a controlled fabrication process.

Now that the possibility or being selected for use on a space science mission exists, more of the specific flight requirements are being addressed. EMI has not been considered in convertors in the past, and generally is difficult to analyze with accuracy during the design process. The linear alternator of a free-piston Stirling convertor is designed for very high efficiency, usually around $90 \%$, and thus has little flux leakage from the permanent magnets. The TDC has less than 1 amp flowing on the power output leads, 
which helps to minimize the radiated emissions. Initial EMI measurements were made on the TDC, however it was not in a controlled environment. The indications were that the EMI was below the requirements for many science missions. Additional tests have been conducted in an EMI chamber at GRC, making use of state-of-the-art EMI measuring equipment. Results from these tests will be reported in the future.

The ability of a free-piston Stirling power convertor to survive the high vibration environment during launch is also critical. A dynamic power conversion system coupled to an isotope heat source will most likely be required to be operating during launch. The TDC, being a technology demonstrator of the principal design, did not have a specific launch load vibration specification applied during the design. A test was recently conducted at the GRC Structural Dynamics Laboratory to characterize an operating TDC when subject to simulated launch loads. The impact on convertor performance of particular interest in this investigation. It was found that the convertor was able to withstand high level random vibration, up to $12.3 \mathrm{Grms}$ while operating at the nominal full power condition. The results of this tests will be reported in detail in the future. This test is viewed as an initial step in determining any necessary modifications to the design that may be required.

For all missions there exists some specification to address the radiation environment to which the power system will subject. Much of the TDC has been fabricated with metals which are influenced very little by radiation, however the TDC does make use of a limited number of organic materials that appear to be unable to tolerate the radiation. It may be possible to eliminate some of the organic materials, as is the case with shrink tubing used on wire connections. An organic compound has been used on the mating piston and cylinder pairs. It is used because of the developmental purpose of the hardware, and is also used in the event of contact between the moving parts during transients such as the during launch loads. Teflon bumpers have been incorporated in the TDC, once again for developmental purposes, and will require a material substitution; no further design change is anticipated. Substitutes for these organic materials are being jointly investigated at GRC, JPL, and LMA.

\section{CONCLUDING REMARKS}

Today's free-piston Stirling power convertors being investigated for space power applications are greatly advanced when compared to earlier convertors. The high conversion efficiency was demonstrated in a number of projects in the past, and now the "potential" for long life has been realized and demonstrated. Studies have indicated that this conversion technology has advantages in applications using either isotope or solar energy as the heat source.
Through a variety of projects funded by both NASA and DOE, areas of concern such as control of multi-convertor systems and vibration reduction have been or are currently being addressed. There is still work to be done regarding EMI, survival of launch load vibration, and radiation tolerance through the substitution or elimination of organic material. These are currently being addressed and results of these efforts should be forthcoming.

\section{REFERENCES}

[1] Schreiber, Jeffrey, "A Deep Space Power System Option Based on Synergistic Power Conversion Technologies," in Space Technology and Applications International Forum, edited by M. S. El-Genk, AIP Conference Proceedings, American Institute of Physics, 2000.

[2] Mason, L.S., "Solar Stirling for Deep Space Applications," in Space Technology and Applications International Fortu, edited by M. S. El-Genk, AIP Conference Proceedings, American Institute of Physics, 2000 .

[3] Mason, L.S., "Technology Projections for Solar Dynamic Power," NASA TM-1999-208851, 1999.

[4] Frazier, T.A., "Advanced Conversion Technology Review Panel Report," Proceedings of the 33rd Intersociety Energy Conversion Engineering Conference, Paper IECEC98-39, 1998.

[5] Mondt, J.F., and Nesmith, B.J., "Advanced Convertor Technology Evaluation and Selection for ARPS," in Space Technology and Applications International Forum, edited by M. S. El-Genk, AIP Conference Proceedings, American Institute of Physics, 1998.

[6] Cassapakis, C., and Thomas, M., "A Power Antenna for Deep Space Missions," in Solar Engineering, edited by J. $\mathbf{H}$. Davidson et al., ASME Conference Proceedings, Book Number H01046, 1996.

[7] Lichodziejewski, D., and Cassapakis, C., "Inflatable Power Antenna Technology," AIAA Paper 99-1074, American Institute of Aeronautics and Astronautics, 1999.

[8] Partch, R.E., Holmes, M.R., and Pearson, J.C., "Inflatable Concentrator Performance Characterization for Space Flight Applications," in Renewable and Advanced Energy Systems for the $21^{\text {st }}$ Century, American Society of Mechanical Engineering, Maui, 1999.

[9] Wong, Wayne A., and Macosko, Robert P., "Refractive Secondary Concentrators for Solar Thermal Applications," NASA TM-1999-209379, 1999. 
[10] Thieme, L.G., Qiu, S., and White, M.A., "Technology Development for a Stirling Radioisotope Power System for Deep Space Missions," Proceedings of the $34^{\text {th }}$ Intersociety Energy Conversion Engineering Conference, Society of Automotive Engineers, 1999, Paper IECEC-99-01-2454.

[11] White, M.A.. Qiu. S, Olan. R.W., and Erbeznik, R.M., "Technology Demonstration of a Free-Piston Stirling Advanced Radioisotope Space Power System," in Space Technology and Applications International Form, edited by M. S. El-Genk, AIP Conference Proceedings, American Institute of Physics, 1999.
[12] Thieme, L.G., Qiu, S., and White, M.A., "Technology Development for a Stirling Radioisotope Power System," in Space Technology and Applications International Forum, edited by M. S. El-Genk, AIP Conference Proceedings, American Institute of Physics, 2000.

[13] Schock, Alfred, Or, Chuen, and Kumar, Vasanth, "Radioisotope Power System Based on Improved Derivative of Existing Stirling Engine and Alternator," in Space Technology and Applications International Forum. edited by M. S. El-Genk, AIP Conference Proceedings, American Institute of Physics, 1999. 


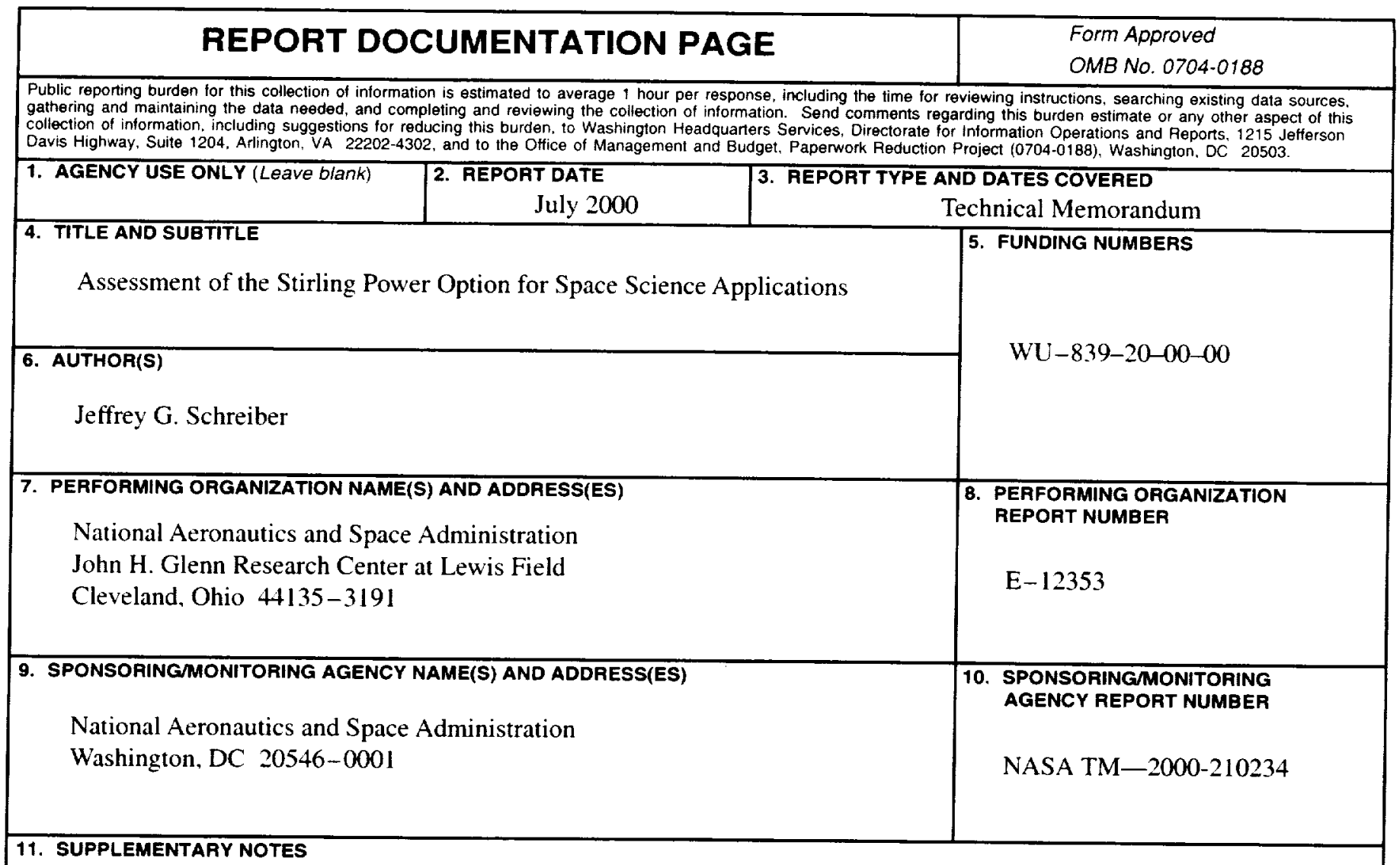

Prepared for the 2000 Aerospace Conference sponsored by the Institute of Electrical and Electronics Engineers Big Sky, Montana, March 18-24, 2000. Responsible person, Jeffrey G. Schreiber, organization code 5490, (216) $433-6144$.

12a. DISTRIBUTION/AVAILABILITY STATEMENT 12b. DISTRIBUTION CODE

Unclassified - Unlimited

Subject Category: 20

Distribution: Nonstandard

This publication is available from the NASA Center for AeroSpace Information. (301) 621-0390.

13. ABSTRACT (Maximum 200 words)

Free-piston Stirling technology efforts in the past typically were intended to address power needs in the multi-kilowatt range. The Stirling power option was attractive primarily because of the high conversion efficiency and potential for long life. In recent years, several technology efforts have focused on the free-piston Stirling power convertor for space power applications, however the more recent efforts are intended to provide power at levels far below one kilowatt. Through a variety of projects funded by both NASA and DOE, the free-piston Stirling convertor technology has successfully demonstrated high efficiency and long life. Other areas of concern, such as control of multi-convertor systems, and vibration reduction have also been addressed. Efforts are being initiated to address issues such as electromagnetic interference (EMI), radiation tolerance of organic materials, and the ability to operate through launch loads and survive with integrity. The status of the technology in these areas will be briefly discussed in this paper.

14. SUBJECT TERMS

Stirling engines; Stirling cycle; Solar energy conversion; Solar collectors 13

15. NUMBER OF PAGES

\begin{tabular}{|l}
13 \\
16. PRICE CODE
\end{tabular}

$\mathrm{A} 03$

\begin{tabular}{|c|c|c|}
\hline $\begin{array}{c}\text { 17. SECURITY CLASSIFICATION } \\
\text { OF REPORT } \\
\text { Unclassified }\end{array}$ & $\begin{array}{c}\text { 18. SECURITY CLASSIFICATION } \\
\text { OF THIS PAGE } \\
\text { Unclassified }\end{array}$ & $\begin{array}{c}\text { 19. SECURITY CLASSIFICATION } \\
\text { OF ABSTRACT } \\
\text { Unclassified }\end{array}$ \\
\hline
\end{tabular}

NSN 7540-01-280-5500

Standard Form 298 (Rev. 2-89)

Prescribed by ANSI Std. Z39-18 298-102 

